\title{
Effects of turbulence conditions on the balance between production and respiration in marine planktonic communities
}

\author{
M. Alcaraz*, C. Marrasé, F. Peters, L. Arin, A. Malits \\ Institut de Ciències del Mar (CMIMA), CSIC. Passeig Marítim de la Barceloneta 37-49, 08003 Barcelona, Spain
}

\begin{abstract}
The control exerted by different intensities and temporal inputs of small-scale turbulence on the balance between $\mathrm{C}$ production and respiration in planktonic communities has been studied by means of laboratory microcosms. The different turbulence conditions modified the temporal pattern of phytoplankton (chlorophyll a) and total biomass development. However, the differences between average values of total (after re-suspension) biomass were not statistically significant. Net primary production (NP) was significantly higher at intermittent turbulence (alternating turbulence and calm periods), with maxima coinciding with the turbulence periods. Respiration (R) was less sensitive to turbulence conditions, but on average was significantly higher under continuous turbulence. The relationships between analysed total particulate organic carbon (TPOC) and theoretical estimates of total organic carbon (according to the daily balance between NP and R) indicated that between 30 and $50 \%$ of NP could be released as dissolved organic carbon. The quotient between daily $\mathrm{C}$ production and $\mathrm{R}$ (indicative of auto- or heterotrophic conditions) was higher under turbulence conditions. Autotrophy lasted for longer periods of time under intermittent turbulence. These results confirm the importance of turbulence in the modulation of the trophic status of the system, opening new perspectives for the study of the mechanisms controlling the selection of planktonic food webs.
\end{abstract}

KEY WORDS: Microcosms · Turbulence $\cdot$ Production $\cdot$ Respiration $\cdot$ Carbon balance

\section{INTRODUCTION}

Primary production and respiration are basic functional properties of marine systems for the control of the fate and turnover rate of biogenic carbon. However, despite the importance of both processes to determine the role of oceans as source or sink of $\mathrm{CO}_{2}$, the nature of their balance, and hence the auto- or heterotrophic character of marine systems is still controversial (del Giorgio et al. 1997, Duarte \& Agusti 1998, Williams 1998), and the control exerted by the different environmental factors poorly understood.

The predominance of either classical or microbial planktonic food webs, closely related to auto- or hetero-

*E-mail: miquel@icm.csic.es trophic conditions, appears to be controlled by matchmismatch mechanisms driven by the mechanical energy field (Cushing 1989, Kiørboe 1993). The selection of 1 of the 2 trophic transfer pathways would therefore be partly dependent on stabilisationdestabilisation cycles induced by external energy inputs and their associated turbulence (Legendre 1981, Holligan et al. 1984a,b, Le Fèvre \& Frontier 1988). However, evidence of the control of food webs by hydrodynamic conditions in natural systems are mainly based on the analysis of extensive or structural properties (i.e. changes in the abundance and biomass of the different trophic components), while the effects on rate processes remain obscure.

The study of the control exerted by small-scale turbulence on aquatic ecosystems has helped to bring in new ideas about plankton ecology (Margalef 1978, 
Legendre et al. 1986). Small-scale turbulence, or its derived shear, drastically modifies the diffusion of dissolved and suspended materials, determines changes in the characteristics of the light field and nutrient supply, and affects the size and chemical composition of phytoplankton (Kiørboe 1993, Estrada \& Berdalet 1997, Arin et al. 2002, Maar et al. 2002), contributing to the selection of 'life forms' (Margalef 1978). Moreover, through enhancing the rate of encounter between organisms (Rothschild \& Osborn 1988, Marrasé et al. 1990), turbulence increases feeding and metabolic rates of zooplankton (Saiz et al. 1992, Alcaraz et al. 1994, Alcaraz 1997).

Significant advances in the study of the ecological effects of turbulence on plankton have been mainly achieved by the use of microcosms. Despite their limited use to 'mimic' natural systems (Carpenter 1996), microcosms enable the separation of turbulence from other covariant factors, such as light and nutrients. At the same time, they facilitate replicability and the control of environmental variables, and allow a quantitative evaluation of the response of plankton communities (Nixon et al. 1980, Estrada et al. 1987, 1988, Alcaraz et al. 1988). However, most of the studies on the effects of turbulence on plankton using microcosms refer to the changes induced in structural properties (biomass, organismal size, taxonomic composition, etc.), while studies on rate processes are quite scarce (Petersen et al. 1997, 1998, Peters et al. 1998, Leclercq et al. 1999).

To determine the effects of turbulence on the functional properties of planktonic ecosystems, turbulence was generated either continuously or intermittently with a similar time-integrated energy supply. At the same time, the observed changes on state variables of plankton (i.e. biomass) were compared with theoretical estimates according to the balance between production and respiration for the different turbulence conditions. The objective was to study the effects of small-scale turbulence on the evolution of the trophic characteristics of the system. The hypothesis was that similar amounts of turbulent mechanical energy had different effects on planktonic systems, depending on the nature of the temporal inputs (i.e. continuous or intermittently supplied). The work is part of a more complex study involving the exploration of the control exerted by the interaction between turbulence, inorganic nutrients and organic matter, on the selection of marine planktonic food webs.

\section{MATERIALS AND METHODS}

Experimental set-up. The experimental set-up consisted of sixteen 151 cylindrical metacrylate containers
(24.2 $\mathrm{cm}$ inner diameter, $34.5 \mathrm{~cm}$ high) installed in a temperature-controlled room. Temperature was maintained at $16 \pm 1^{\circ} \mathrm{C}$ and illumination was provided by a series of fluorescent lights $\left(225 \mu \mathrm{mol}\right.$ photons $\left.\mathrm{m}^{-2} \mathrm{~s}^{-1}\right)$ on a 12:12 h light:dark photoperiod. More details about the experimental set-up can be found in Alcaraz et al. (2001) and Peters et al. (2002).

Eight microcosms were not subjected to turbulence and were considered as controls (hereafter S microcosms). For another 8 microcosms, 4 were continuously subjected to turbulence (dissipation rate of turbulent kinetic energy, $\varepsilon=0.054 \mathrm{~cm}^{2} \mathrm{~s}^{-3}$, hereafter $\mathrm{T}$ microcosms) and 4 to alternating periods of $2 \mathrm{~d}$ with or without turbulence starting with $2 \mathrm{~d}$ under turbulence $(\varepsilon=$ $0.140 \mathrm{~cm}^{2} \mathrm{~s}^{-3}$, hereafter TI microcosms). These turbulence values are within the intensity range found in coastal areas (Kiørboe \& Saiz 1995). Due to the different dissipation rate of turbulent kinetic energy, $\mathrm{T}$ and TI microcosms should receive similar integrated amounts of kinetic energy over the experimental run, even though the length of time under turbulence were different. Turbulence was induced by the vertical oscillation of grids. The oscillation amplitude and frequency were set to achieve the desired turbulence dissipation rates (Peters \& Redondo 1997). Microcosms were filled with coastal seawater taken 3 to $4 \mathrm{~km}$ off Masnou harbour, $25 \mathrm{~km}$ north of Barcelona, at $1 \mathrm{~m}$ depth. Water was filtered through $150 \mu \mathrm{m}$ mesh nylon netting to discard large zooplankters. After which, it nutrient-enriched with $\mathrm{P}$ and $\mathrm{N}$ (final concentration: $0.6 \mu \mathrm{M} \mathrm{PO}_{4}, 10 \mu \mathrm{M} \mathrm{NO} 3$ ).

Sampling protocols and measured variables. Two sampling protocols were designed, depending on the volume of water required to carry out the analyses of the corresponding variables. Community $\mathrm{O}_{2}$ metabolism (net primary production, NP; respiration, R) and phytoplankton biomass (chlorophyll $a$, chl a), which were either measured 'in situ' by probes or required only small volumes of water (ca. $50 \mathrm{ml}$ ) were estimated daily. The stroke length of the turbulence-generating grid was shortened in order to maintain the energy dissipation rate equal to the initial conditions when the water volume decreased (Peters et al. 2002).

For some variables requiring large volumes of water, stroke length compensation was not possible (i.e. for zooplankton biomass at least 41 samples were used). For other variables, special manipulations like resuspension of settled material (i.e. to sample total chl a and total particulate carbon and nitrogen) would substantially change the experimental conditions. For these reasons, every other day $2 \mathrm{~S}, 1 \mathrm{~T}$ and $1 \mathrm{TI}$ microcosms were chosen randomly and exhaustively sampled. Although this sampling scheme reduced the number of replicates for each experimental condition, the remaining microcosms allowed the estimation of 
the evolution of the plankton community for all the experimental conditions until the end of the experiment.

The variables measured every other day were total (after re-suspension) phytoplankton biomass taken as a measure of chl a $(\mathrm{T} \mathrm{chl} \mathrm{a),} \mathrm{and} \mathrm{suspended} \mathrm{and} \mathrm{total}$ (after re-suspension) particulate organic carbon and nitrogen (POC, PON and TPOC, TPON, respectively).

Samples were taken by siphoning water through a glass tube with its end placed at $1 / 2$ of the radius distance from the centre of the microcosm, and at about $15 \mathrm{~cm}$ from its bottom.

Measurement of NP and R. Rates of community production during daylight hours and the nocturnal consumption (community respiration) of dissolved $\mathrm{O}_{2}$ were calculated as the regression coefficients of the linear equations describing the respective increase and decrease of dissolved $\mathrm{O}_{2}$; they were then transformed into daylight $\mathrm{C}$ production and nocturnal respiration, respectively. The regression equations explained from 84 to $99 \%$ of the variance observed. Daily NP was calculated as the difference between community production rate during the day and nocturnal respiration rate. Daily gross production (GP) was calculated as NP $+\mathrm{R}$, assuming no differences between diurnal and nocturnal respiration rates. In randomly selected microcosms $(2 \mathrm{~S}, 1 \mathrm{~T}$ and $1 \mathrm{TI})$, ENDECO-O $\mathrm{O}_{2}$ electrodes were installed as described in Alcaraz et al. (2001), to measure temperature and dissolved $\mathrm{O}_{2}$ concentration at $15 \mathrm{~min}$ intervals. The dissolved $\mathrm{O}_{2}$ concentration along the experiment significantly deviated from saturation conditions, owing to the biological activity. Thus, the measured concentrations were corrected for $\mathrm{O}_{2}$ losses and gains due to the air-water exchange. The rate of $\mathrm{O}_{2}$ exchange across the water-atmosphere interface, $\phi$, $\mu \mathrm{mol} \mathrm{O}_{2} \mathrm{~m}^{-2} \mathrm{~h}^{-1}$, was estimated according to the Fick's law:

$$
\phi=\Delta_{\mathrm{O}_{2}} K_{\mathrm{O}_{2}}
$$

where the air-water concentration gradient, $\Delta_{\mathrm{O}_{2}}$ can be directly obtained from the difference between measured $\mathrm{O}_{2}$ and the saturation concentration corresponding to the experimental temperature and salinity conditions, and $K_{\mathrm{O}_{2}}$ the $\mathrm{O}_{2}$ transfer velocity, depends on the rate of turbulent diffusion, $\varepsilon$ (Alcaraz et al. 2001). The corresponding values of $\mathrm{O}_{2}$ transfer velocity $\left(K_{\mathrm{O}_{2}}\right)$ for the different turbulence conditions were obtained according to the equations given in Alcaraz et al. (2001).

Daily NP and $\mathrm{R}$ in terms of $\mathrm{O}_{2}$ were transformed into $\mathrm{C}$ production and metabolic losses, respectively. We used an average photosynthetic quotient (molar ratio between $\mathrm{O}_{2}$ produced and $\mathrm{C}$ assimilated), $\mathrm{PQ}=1.2$, and a respiratory quotient (molar ratio between $\mathrm{CO}_{2}$ produced and $\mathrm{O}_{2}$ consumed), $\mathrm{RQ}=0.97$ (Williams et al.
1979, Omori \& Ikeda 1984). Results were expressed in

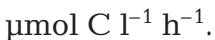

The evolution of the trophic conditions along the experiment were measured as the quotient GP/R, with GP being equivalent to $\mathrm{NP}+\mathrm{R}$. GP/R $>1$ represented net autotrophy, GP/R $=1$ trophic balance and GP/R $<1$ net heterotrophy.

Particulate matter and phytoplankton biomass. Phytoplankton biomass, taken as a measure of chl $a_{1}$ was estimated daily by fluorimetry in $90 \%$ acetone extracts (Yentsch \& Menzel 1963). Total (after resuspension) chl a was similarly estimated every other day in the sacrificed microcosms.

For the analysis of particulate organic matter, between 250 and $1000 \mathrm{ml}$ water samples were taken every other day before and after stirring the selected microcosms in order to re-suspend the settled material (suspended, POC and PON and total, TPOC and TPON, respectively). Water samples were filtered through GF/F glass fibre filters, dried and stored for further analysis of organic carbon and nitrogen by means of a Carlo-Erba elemental analyser. As precombusted glass fibre filters become frail and their analysis requires additional manipulation (i.e. to roll them into small balls coated with Sn-foil), we used non-combusted filters. On 10 randomly chosen blank filters, the organic $\mathrm{C}$ and $\mathrm{N}$ contents were analysed, resulting in an average of $38.73 \mu \mathrm{C} \mathrm{C} \mathrm{(CV} \mathrm{12.3 \% )} \mathrm{and}$ $3.48 \mu \mathrm{g} \mathrm{N}$ (CV 7.6\%) per filter. These values were then substracted from the sample analyses, and the results expressed in $\mu \mathrm{C} \mathrm{Cl}^{-1}$ and $\mu \mathrm{g} \mathrm{N}{ }^{-1}$.

The theoretical accumulation of assimilated total organic carbon (TOC) was calculated as the increase of carbon resulting from the initial POC concentration, and the daily balance between NP and R for the different turbulence conditions.

\section{RESULTS}

\section{Biomass parameters}

A common response of the community to the different treatments was evident in the development of a phytoplankton bloom, as seen by the peak in chl a (Fig. 1). However, for TI conditions, chl a showed a double peak coinciding with the turbulence periods. The first peak occurred on Day 2, then decreased during the still phase, and again peaked at the end of the new turbulence period. The single peak in $\mathrm{S}$ and $\mathrm{T}$ conditions occurred on Day 3. Turbulence resulted in significantly higher chl a concentration than still conditions (ANOVA, $p<0.0027$ ). Average chl $a$ for T and TI almost doubled that corresponding to $\mathrm{S}$ conditions. The temporal evolution of total chl a (after re-suspension, 

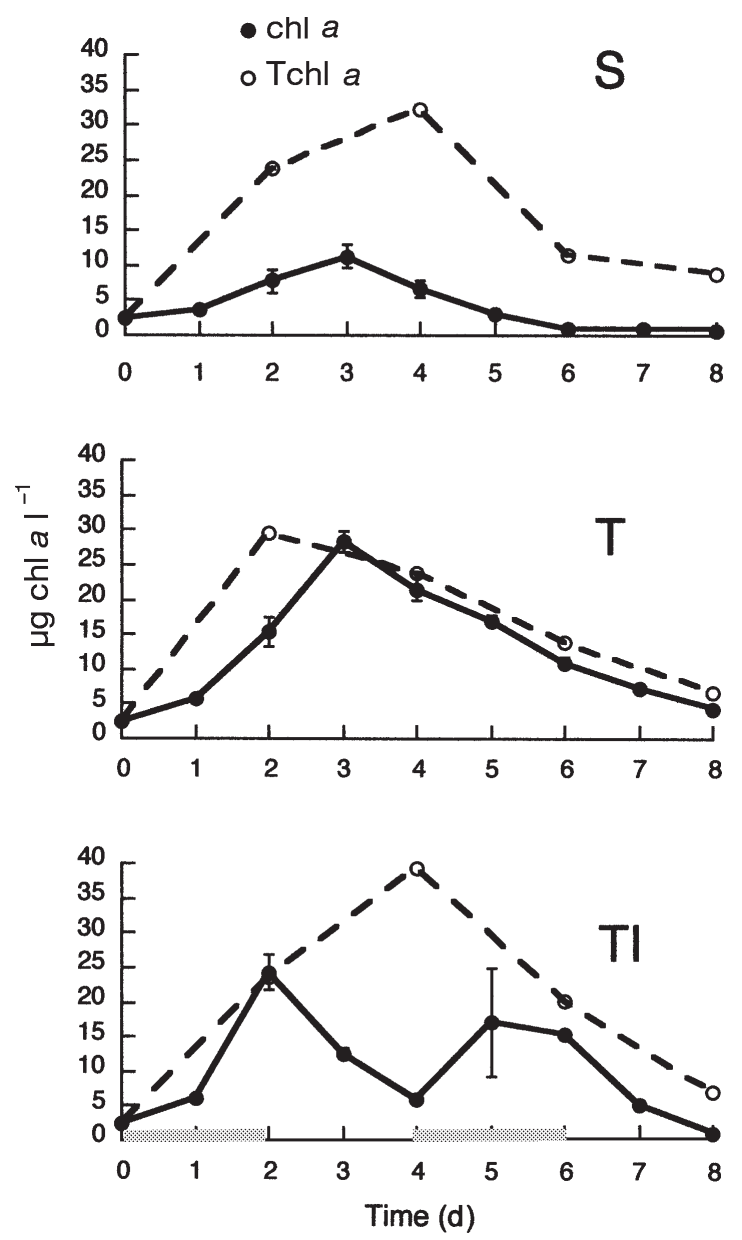

Fig. 1. Dynamics of chl a concentration throughout the experiment for the 3 experimental conditions. S: still; T: continuous turbulence; TI: intermittent turbulence. Vertical lines represent SD. Horizontal bars in abscissae indicate the periods of turbulence for TI conditions

T chl a) is also represented in Fig. 1. The settled fraction averaged $78 \%$ for still (S) conditions (from 75 to $95 \%$ of total, suspended plus settled), while $\mathrm{T}$ microcosms averaged $32 \%$. For TI conditions, the settled

Table 1. Time course of the $\mathrm{C}: \mathrm{N}$ ratio (atoms) of suspended and re-suspended particulate organic matter for $\mathrm{S}, \mathrm{T}$ and TI conditions. -s: suspended; -res: after re-suspension. AV: average values. SD: standard deviation

\begin{tabular}{|lrrrrrr|}
\hline Day & S-s & S-res & T-s & T-res & TI-s & TI-res \\
\hline 0 & 6.4 & 6.4 & 6.4 & 6.4 & 6.4 & 6.4 \\
2 & 6.5 & 7.5 & 5.5 & 7.0 & 4.1 & 7.3 \\
4 & 9.1 & 14.1 & 17.0 & 18.7 & 3.4 & 16.2 \\
6 & 9.8 & 10.9 & 20.6 & 21.0 & 17.1 & 22.4 \\
8 & 5.8 & 10.9 & 12.5 & 12.8 & 5.9 & 9.6 \\
AV & 7.5 & 10.0 & 12.4 & 12.2 & 7.4 & 12.4 \\
SD & 1.8 & 2.7 & 6.5 & 6.4 & 5.6 & 6.8 \\
\hline
\end{tabular}

Table 2. Changes with time of the specific C-production rates $\left(\mathrm{d}^{-1}\right)$ and doubling time (d) for the different experimental conditions. TPOC: for total (after re-suspension) particulate carbon; POC: for suspended particulate carbon. S, T and TI, the different experimental conditions, as explained in the text. Negative values represent the specific respiratory carbon losses and the time to consume the particulate carbon as respiratory losses, respectively

\begin{tabular}{|c|c|c|c|c|c|c|}
\hline Day & TPOC S & TPOC & TPOC & POC S & POC T & POC TI \\
\hline \multicolumn{7}{|c|}{ Specific C-production rates $\left(\mathrm{d}^{-1}\right)$} \\
\hline 2 & 0.06 & 0.02 & 0.16 & 0.12 & 0.03 & 0.23 \\
\hline 3 & & & & 0.61 & 0.56 & 1.04 \\
\hline 4 & 0.19 & 0.18 & 0.10 & 0.59 & 0.21 & 0.25 \\
\hline 5 & & & & 0.09 & 0.03 & 0.08 \\
\hline 6 & -0.03 & -0.10 & 0.03 & -0.13 & -0.10 & 0.04 \\
\hline 7 & & & & -0.56 & -0.21 & 0.00 \\
\hline 8 & -0.10 & -0.22 & -0.11 & -0.43 & -0.23 & -0.12 \\
\hline \multicolumn{7}{|c|}{ Doubling time (d) } \\
\hline 2 & 15.66 & 48.22 & 6.27 & 8.43 & 35.45 & 4.36 \\
\hline 3 & & & & 1.65 & 1.79 & 0.97 \\
\hline 4 & 5.24 & 5.41 & 9.98 & 1.69 & 4.81 & 3.96 \\
\hline 5 & & & & 10.94 & 31.34 & 13.12 \\
\hline 6 & -29.54 & -10.47 & 31.41 & -7.71 & -9.94 & 23.49 \\
\hline 7 & & & & -1.77 & -4.78 & 237.88 \\
\hline 8 & -9.86 & -4.47 & -8.76 & -2.35 & -4.36 & -8.27 \\
\hline
\end{tabular}

chl a fraction was $56 \%$ on average. The suspended POC and PON followed different time courses (Fig. 2). While the temporal evolution of PON was similar to that of chl a for all the experimental conditions, POC changes were, as expected, similar to the temporal evolution of the C:N ratios (Fig. 2, Table 1). Average values of suspended PON and POC in turbulent microcosms were higher than in still ones. The highest average values corresponded to $\mathrm{T}$ conditions.

TPON and TPOC (after re-suspension) are also represented in Fig. 2. TPON increased steadily through the experiment, but re-suspended TPOC decreased at the end of the experiment, following a trend similar to that of the corresponding $\mathrm{C}: \mathrm{N}$ ratios (Table 1). The average values of TPON were similar for the different experimental conditions. However, TPOC for T and TI were slightly higher than for $\mathrm{S}$ conditions, and the same occurred for C:N ratios (Table 1).

\section{Primary production and respiration}

The raw data and corrected values of dissolved $\mathrm{O}_{2}$ concentration presented oscillations of $12 \mathrm{~h}$ periods coinciding with the experimental light-dark cycles (Fig. 3). The rate of community production during the day (Fig. 4A) followed trends similar to the evolution of chl $a$ and appeared to be related to turbulence intensity. 

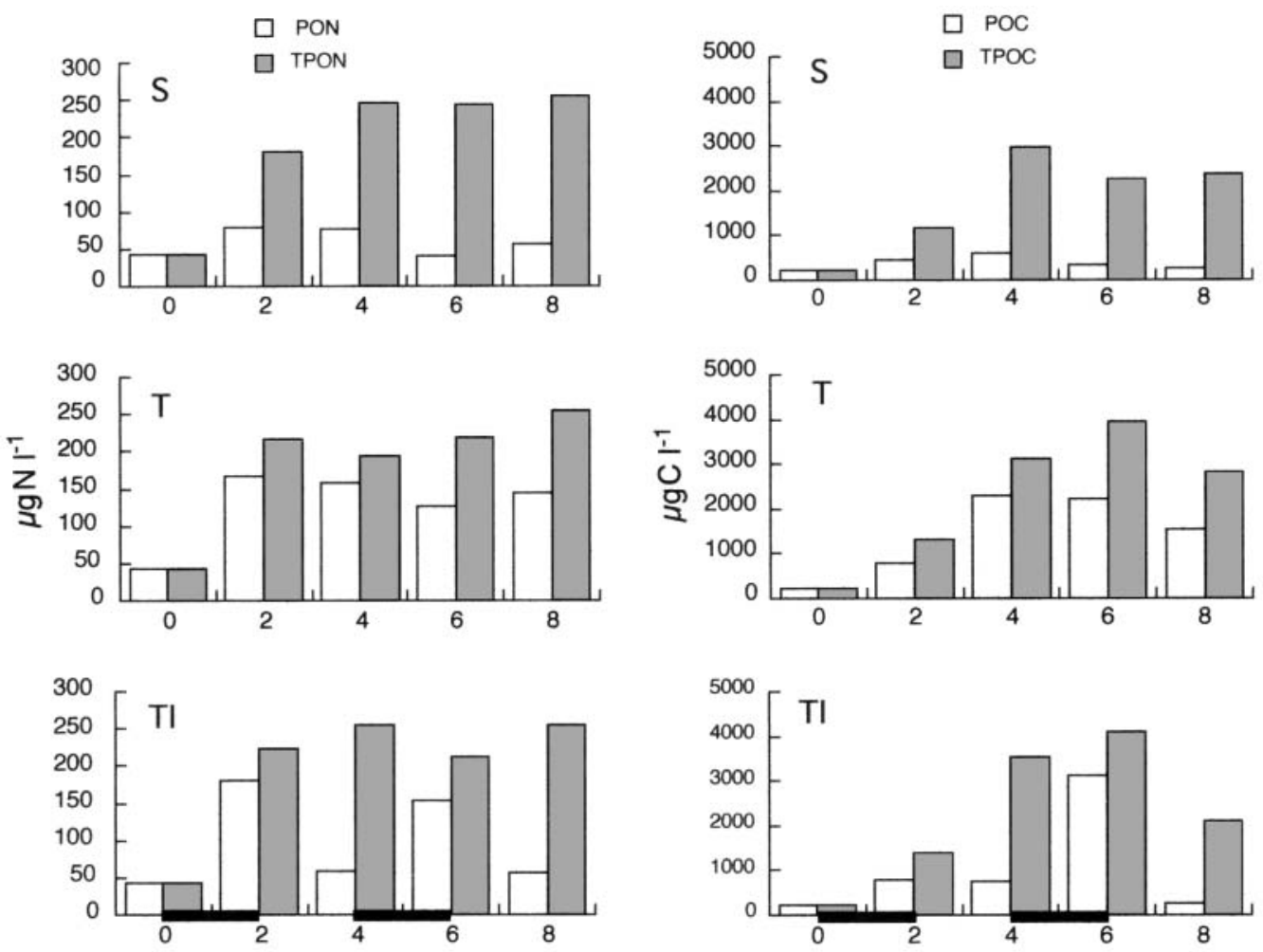

Time (d)

Fig. 2. Particulate organic carbon (POC) and nitrogen (PON) concentration along the experiment for S (average of 2 microcosms with the electrodes), T and TI conditions. Horizontal bars in abscissae as in Fig. 1

NP rates (Fig. 5A) were also related to turbulence intensity and followed approximately the changes observed in chl a. While negative values of NP occurred after Day 4 in $\mathrm{S}$ and $\mathrm{T}$ conditions, positive NP lasted for a further $2 \mathrm{~d}$ in TI conditions. The changes of NP in TI microcosms followed the cycles of turbulence-calm conditions, peaking on Day 2, decreasing during the first calm period (Days 3 and 4), and again slightly increasing on Day 5. Thereafter, NP decreased to negative values. TI conditions resulted in the highest NP rates.

The slope of the regression equations relating chl a and NP, equivalent to the productivity index (Fig. 5B), ranged from $2.2(\mathrm{~T})$ to $3.9(\mathrm{~S})$. However, the regression equations were significant only for $\mathrm{S}$ and TI conditions.

Specific NP rates (quotient NP/POC or NP/TPOC) are indicated in Table 2. The production per unit of suspended biomass (NP/POC) was higher for S and TI

Fig. 3. Time changes of measured $\mathrm{O}_{2}$ concentration throughout the experiment for $\mathrm{S}, \mathrm{T}$ and TI conditions, and the corresponding values after corrected for water-atmosphere exchanges. The 12:12 $\mathrm{h}$ oscillation corresponds to the daylight increase (net production) and nocturnal decrease (respiration), respectively. For TI conditions, light and dark areas represent calm and turbulence periods, respectively
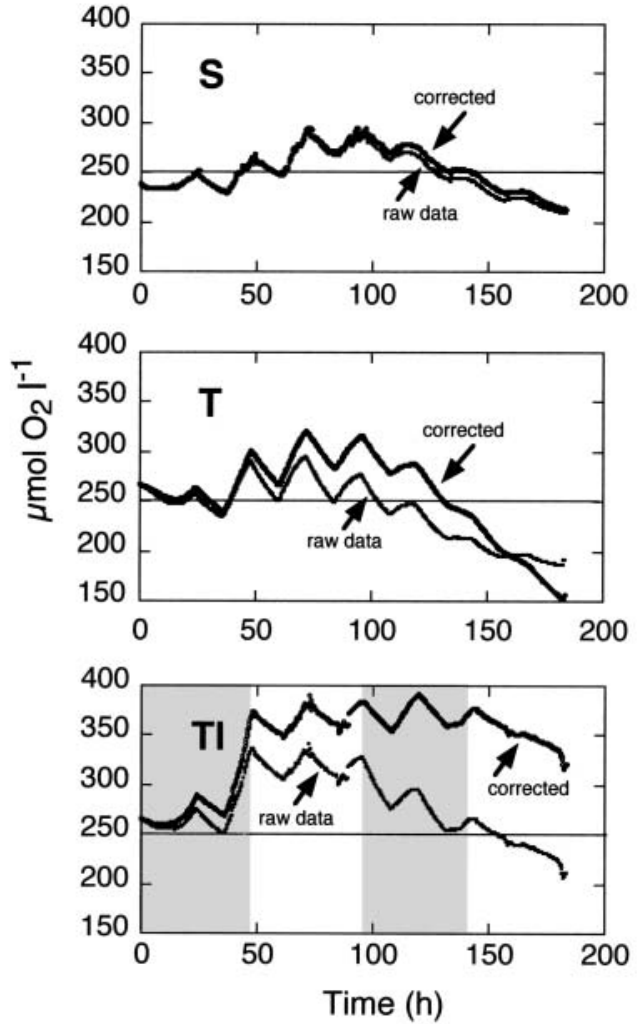


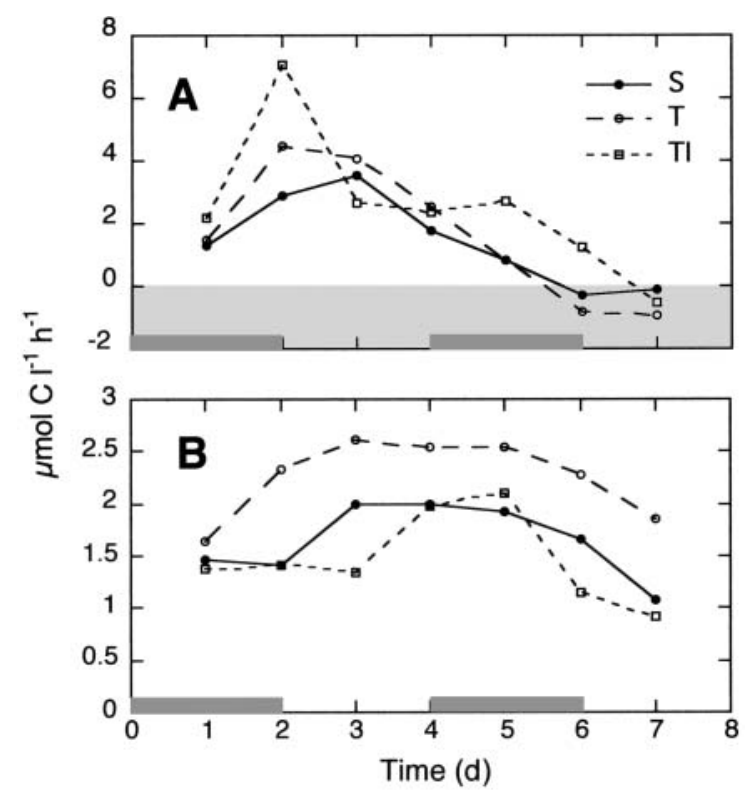

Fig. 4. (A) Time changes of photosynthetic rates during daylight hours and (B) nocturnal respiration rates, both in $\mu \mathrm{mol} C$ $\mathrm{l}^{-1} \mathrm{~h}^{-1}$, for the $\mathrm{S}, \mathrm{T}$ and TI experimental conditions. The shaded area represents values of negative photosynthesis (respiration higher than photosynthesis during daylight hours). Horizontal bars in abscissae as in Fig. 1

conditions. Positive values (positive $\mathrm{C}$ balance) lasted longer for TI conditions, both when specific rates were calculated with respect to suspended (POC) or re-suspended (TPOC) carbon. The highest turnover rates, more than 1 duplication $\mathrm{d}^{-1}$, corresponded to TI conditions (Day 2; Table 2).

Community respiration rates $\left(\mathrm{R}_{i}\right.$ Fig. $\left.4 \mathrm{~B}\right)$ were also highly influenced by the turbulence conditions. The highest $\mathrm{R}$ values corresponded to continuous turbulence ( $\mathrm{T}$ microcosms), while there were no statistical differences between $\mathrm{S}$ and TI microcosms. The specific respiration rates for the different turbulence conditions (R/POC and R/TPOC) followed a similar trend, with higher values for $\mathrm{T}$ conditions (Fig. 6). The relationships between analysed, total TPOC and the predicted daily accumulation of assimilated total carbon (particulate plus dissolved TOC) for the different turbulence conditions, are represented in Fig. 7. The balance between $\mathrm{C}$ produced and respired, when accumulated through the experiment, was in good accordance with analysed values. For S and TI conditions, the correlation was statistically significant. For T microcosms, the correlation was significant after removing the outlier point marked with an asterisk in Fig. 7. Analysed TPOC concentrations were from 30 to $50 \%$ lower than predicted TOC values.

The changes induced by the different turbulence conditions to the ratio between GP $(\mathrm{NP}+\mathrm{R})$ and respi- ration $(\mathrm{GP} / \mathrm{R})$, indicative of the trophic characteristics of the system, are represented in Fig. 8. The tendencies throughout the experiment were similar for the different turbulence conditions, the quotient reaching the maximum values on Day 2. However, the lowest values corresponded to $\mathrm{T}$ conditions and the longest maintenance of the autotrophic conditions (quotient values $>1$ ) corresponded to TI conditions.

\section{DISCUSSION}

The positive relation observed between the dissipation rate of turbulent kinetic energy $(\varepsilon)$ and the intensity of the phytoplankton blooms (suspended chl a) seems to confirm the role attributed to exosomatic (mechanical) energy for the control of planktonic NP in natural systems (Margalef 1978, Legendre et al. 1986, amongst others). Marrasé (1986), Estrada et al. (1987, 1988) and Arin et al. (2002) obtained similar results in microcosm experiments. Petersen et al. (1998) found slight differences in average chl a amongst microcosms under a range of mixing schedules during a

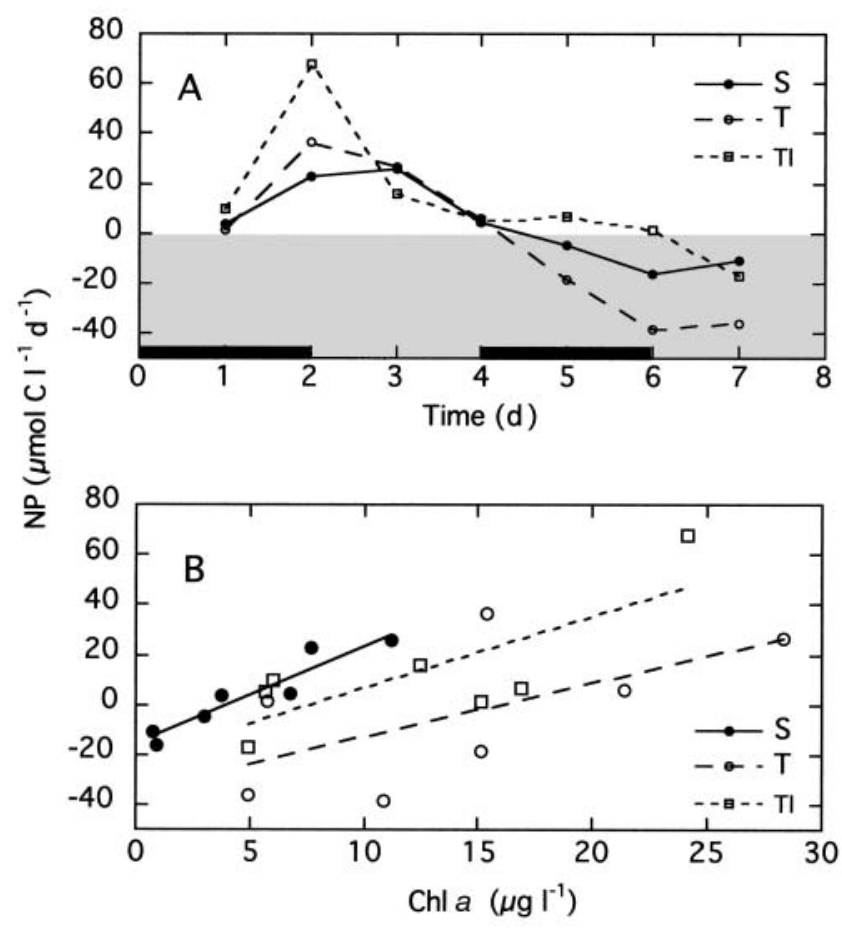

Fig. 5. (A) Time changes of net production (daily balance between $\mathrm{C}$ produced and respired, NP) through the experiment for $\mathrm{S}, \mathrm{T}$ and TI conditions. The shaded area corresponds to net carbon losses. (B) Relationships between chl a ( $\mu \mathrm{g} \mathrm{chl} \mathrm{a}$

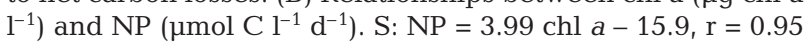
$(\alpha<0.05) ; \mathrm{T}: \mathrm{NP}=2.16 \mathrm{chl} a-34.7, \mathrm{r}=0.62, \mathrm{~ns} ; \mathrm{TI}: \mathrm{NP}=2.87$ chl $a-22.3, \mathrm{r}=0.78(\alpha<0.05)$. Horizontal bars in abscissae as in Fig. 1 


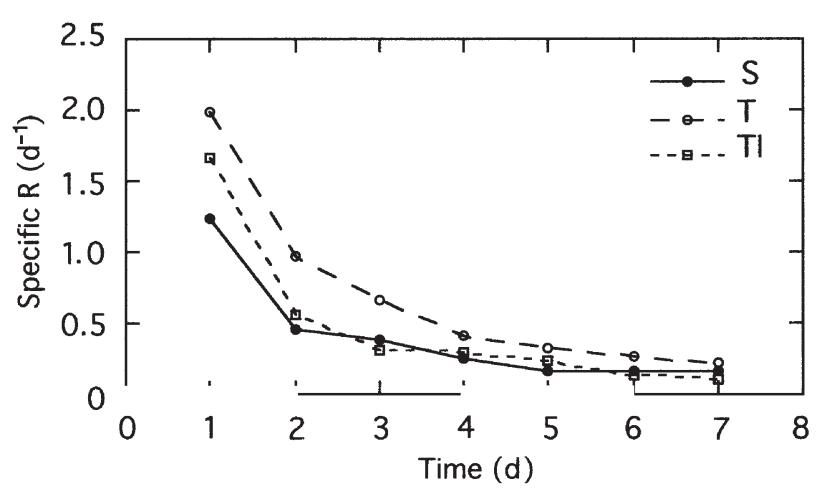

Fig. 6. Time changes throughout the experiment of the specific respiration (R) for $\mathrm{S}, \mathrm{T}$ and TI conditions. Horizontal bars in abscissa as in Fig. 1

'pre-bloom' situation; however, the addition of nutrients resulted in significant effects for different mixing schedules, both when considering the suspended fraction only and including the periphyton. In our case, the effects of the different turbulence conditions were significant only for the suspended fraction of chl $a$, as well as for C:N ratios, and POC and PON values.

The examples of higher values of suspended phytoplankton biomass under turbulence could be attributed in part to differences in the sedimentation and resuspension rates of particulate material. The lack of significant differences in total (after re-suspension) chl a (T chl a; Fig. 1), as well as in re-suspended carbon and nitrogen (TPOC, TPON; Fig. 2) for the different experimental conditions seem to suggest that the differences could be attributed to differences in sedimentation and re-suspension rates for the different turbulence conditions. However, as turbulence seems to accelerate rate processes both for NP and R (Fig. 4), end point biomass balances could be misleading. Simultaneous measurements of high frequency time changes of biomass, NP and R are required to discern this issue.

Estimates of the $\mathrm{O}_{2}$ community metabolism in opentop microcosms are problematic. The use of BOD (biological oxygen demand) bottles in incubation experiments requires relatively large volumes of water; therefore, reducing the temporal resolution of the measurements if experiments are performed in relatively small-sized microcosms. Other limitations of the use of BOD bottles are the change of the surface-volume ratios, as well as the restriction of the measurements to a fraction of the community (the suspended fraction), instead of the whole microcosm. In contrast, oxygen electrodes provide simple, precise estimations of the 'in situ' changes in dissolved $\mathrm{O}_{2}$ for the whole community and their use allow estimates of $\mathrm{O}_{2}$ metabolic rates with a high temporal resolution. The only problem to derive NP and R rates from the measured day-night

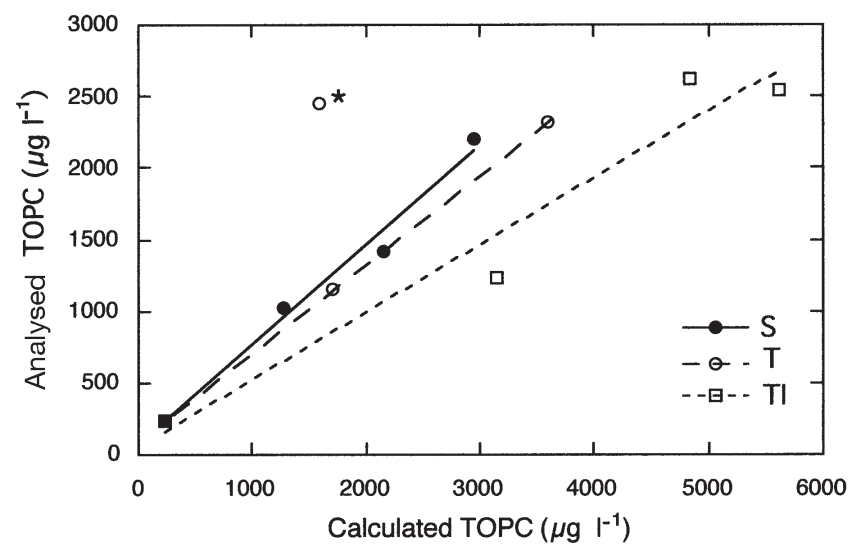

Fig. 7. Relationships between analysed total (after resuspension) particulate organic carbon (TPOC, ordinates) and calculated total organic carbon (TOC, including the fraction released in dissolved form, abscissae). The calculations were made according to the daily changes in the balance between $\mathrm{C}$ production and respiration (R). Data in $\mu \mathrm{g} \mathrm{Cl}^{-1}$. S: TPOC $=0.70$ TOC $+68.8, r=0.99(\alpha<0.05) ;$ T: TPOC $=0.62 \mathrm{TOC}+90.2, \mathrm{r}=$ $1^{*}(\alpha<0.05)$; TI: TPOC $=0.47$ TOC $+42.26, \mathrm{r}=0.9(\alpha<0.05)$.

* When removing the outlier point marked with asterisk

changes of dissolved $\mathrm{O}_{2}$, is the correction for the wateratmosphere $\mathrm{O}_{2}$ exchange rates, which are a consequence of deviations from the equilibrium conditions due to biological activity (Petersen et al. 1998, Leclercq et al. 1999). However, when turbulence conditions are known, the parameters to determine the wateratmosphere exchange rates can be precisely calculated (Alcaraz et al. 2001).

In our experiment, the rates of $\mathrm{C}$ fixation during daylight hours appeared directly related to the values of $\varepsilon$ (Fig. 4A), probably due to the enhancement of the advective transport of nutrients to phytoplankton cells under turbulence (Karp-Boss et al. 1996, Estrada \& Berdalet 1997). Respiration, on the contrary, was significantly higher for intermediate turbulence levels $(\mathrm{T})$,

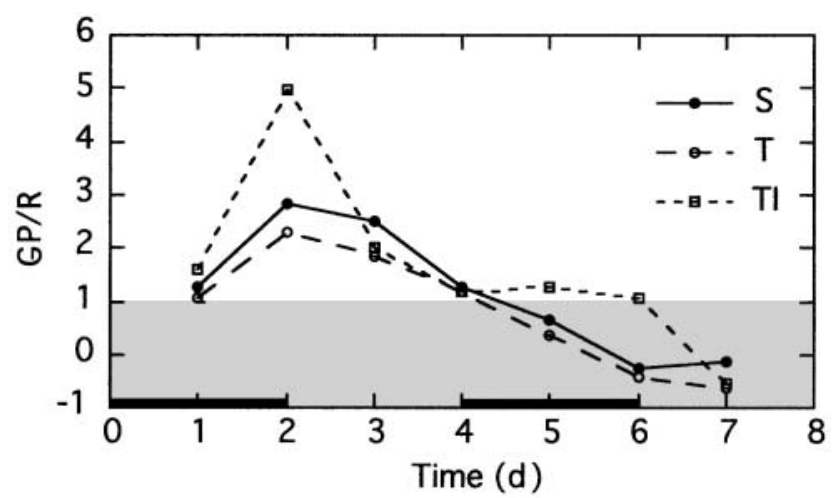

Fig. 8. Time changes throughout the experiment of the quotient gross production/respiration (GP/R) for $\mathrm{S}, \mathrm{T}$ and TI conditions. The shaded area corresponds to heterotrophic situations $(\mathrm{GP} / \mathrm{R}<1)$. Horizontal bars in abscissa as in Fig. 1 
even if $\mathrm{C}$-specific respiration rates are considered. A possible explanation could be the existence of a domeshaped response of respiration to $\mathrm{T}$, as observed by Alcaraz et al. (1994) for the relation turbulencetemperature-respiration rates, and MacKenzie et al. (1994) for the relation between ingestion rates of larval fish and turbulence. The relatively high NP $\mu^{-1} \mathrm{chl} \mathrm{a}$ in $\mathrm{S}$ microcosms (productivity index; Fig. 5B) could be due to a higher chl a content per cell in $\mathrm{T}$ and TI microcosms (photoacclimation), as a consequence of the reduction of light intensity in turbulent microcosms (higher concentration of particulate matter).

The observed differences amongst turbulence conditions in NP and R are a consequence not only of differences in phytoplankton ( $\mathrm{chl}$ a) or total (TPOC, TPON) biomass, but to changes in the specific $\mathrm{O}_{2}$ metabolic rates. The double peak of NP rates for intermittent turbulence (TI), following the turbulence-calm periods, could depend, as mentioned above, on changes in the accessibility of nutrients to phytoplankton under turbulence (Karp-Boss et al. 1996, Estrada \& Berdalet 1997, Peters \& Marrasé 2000). These results contrast with the negligible effects of turbulence on ecosystem metabolism (NP and R) found by Petersen et al. (1998) in mesocosms experiments for a similar range of turbulence.

The good relationships between the analysed values of TPOC and theoretically calculated TOC seem to confirm the validity of the estimated metabolic rates. The analysed values correspond to POC, while the calculated ones also include the fraction released in dissolved form. According to the regression coefficients of the equations relating analysed and calculated carbon, between 30 and $50 \%$ of the assimilated carbon is released in dissolved form. These values are similar to those obtained by Søndergaard et al. (2000) in mesocosms (about $50 \%$ for experiments of similar duration), and slightly higher than those found by Morán \& Estrada (2001) in natural communities of the Western Mediterranean (up to $30 \%$ ).

The temporal changes in the balance between GP and $\mathrm{R}$ also appear to be significantly influenced by the turbulence characteristics. The changes in the quotient GP/R reflect the importance of the intensity and timepattern of turbulence inputs on the short-term evolution of the trophic status of a system affected by a nutrient pulse. The longer persistence of the autotrophic conditions for intermittent turbulence (TI), the hydrodynamic conditions prevailing in natural systems, appear to be due to the enhancing effect of NP rates at the onset of the second turbulence period. The re-start of the turbulence, apart from the mentioned resuspension of particulate matter, had negligible effects on specific R rates. However, the relatively higher $\mathrm{C} / \mathrm{N}$ ratios of re-suspended matter in $\mathrm{T}$ and $\mathrm{TI}$ conditions suggest the importance of turbulence for the export of C-rich particulate organic matter. Similar effects of turbulence on the stoichiometry of particulate matter composition has been observed by Maar et al. (2002).

We can conclude that the use of continuous or semicontinuous 'in situ' measurement of changes on dissolved $\mathrm{O}_{2}$ concentration (once corrected for wateratmosphere exchange rates) is a valid method to derive $\mathrm{O}_{2}$ metabolism in aquatic systems open to the atmosphere. The only restriction is the necessity for a precise determination of water-atmosphere $\mathrm{O}_{2}$ exchange rates, which can be easily encompassed if turbulent energy dissipation rates are known. From our results, we can conclude that part of the subsidising effects of external energy (turbulence) on ecosystem metabolism have been demonstrated, at least for coastal planktonic communities, and despite the limited experimental range of turbulence intensity and frequency of energy pulses. However, further studies on the combined effects of mechanical energy (turbulence), inorganic nutrients and organic matter inputs at different frequencies are needed in order to obtain a more precise view of the relevant factors determining the trophic status of the system.

Acknowledgements. The authors are indebted to M. Estrada for her helpful comments. The manuscript was also greatly improved thanks to the comments of 3 unknown referees whose suggestions helped to clarify some concepts. Oscar Guadayol helped in the laboratory. The study was financially supported by grants MAR98-0854 (SERET) and REN20011693/MAR (ZOOTRANSFER) from the CICYT, and EVK3CT-2000-00022 (NTAP) and EVK3-CT99-00015 (BIOHAB) from the EU. F.P. was supported by a contract from the Spanish Ministry of Science and Culture.

\section{LITERATURE CITED}

Alcaraz M (1997) Copepods under turbulence: grazing, behaviour and metabolic rates. Sci Mar 61(Suppl 1):177-195

Alcaraz M, Saiz E, Marrasé C, Vaqué D (1988) Effects of turbulence on the development of zooplankton biomass and copepod populations in marine microcosms. Mar Ecol Prog Ser 49:117-125

Alcaraz M, Saiz E, Calbet A (1994) Small-scale turbulence and zooplankton metabolism: effects of turbulence on heartbeat rates of planktonic crustaceans. Limnol Oceanogr 39:1465-1470

Alcaraz M, Marrasé C, Peters F, Arin L, Malits A (2001) Seawater-atmosphere $\mathrm{O}_{2}$ exchange rates in open-top laboratory microcosms: application for continuous estimates of planktonic primary production and respiration. J Exp Mar Biol Ecol 257:1-12

Arin L, Marrasé C, Maar M, Peters F, Sala MM, Alcaraz M (2002) Combined effects of nutrients and small-scale turbulence in a microcosm experiment. I. Dynamics and sizedistribution of osmotrophic plankton. Aquat Microb Ecol 29:51-61

Carpenter SR (1996) Microcosm experiments have limited relevance for community and ecosystem ecology. Ecology $77: 677-680$ 
Cushing DH (1989) A difference between ecosystems in strongly stratified waters and those that are only weakly stratified. J Plankton Res 11:1-31

del Giorgio P, Cole JJ, Cimbleris A (1997) Respiration rates in bacteria exceed phytoplankton production in unproductive aquatic systems. Nature 385:148-151

Duarte CM, Agusti S (1998) The $\mathrm{CO}_{2}$ balance of unproductive aquatic ecosystems. Science 281:234-236

Estrada M, Berdalet E (1997) Phytoplankton in a turbulent world. Sci Mar 61(Suppl 1):125-140

Estrada M, Alcaraz M, Marrasé C (1987) Effects of turbulence on the composition of phytoplankton assemblages in marine microcosms. Mar Ecol Prog Ser 38:267-281

Estrada M, Marrasé C, Alcaraz M (1988) Phytoplankton response to intermittent stirring and nutrient addition in marine microcosms. Mar Ecol Prog Ser 48:225-234

Holligan PM, Harris RP, Newell RC, Herbour DS and 5 others (1984a) Vertical distribution and partitioning of organic carbon in mixed, frontal and stratified waters of the English Channel. Mar Ecol Prog Ser 14:111-127

Holligan PM, Williams PJLeB, Purdie D, Harris RP (1984b) Photosynthesis, respiration and nitrogen supply of plankton populations in stratified, frontal and tidally mixed shelf waters. Mar Ecol Prog Ser 17:201-213

Karp-Boss L, Boss E, Jumars PA (1996) Nutrient fluxes to planktonic osmotrophs in the pressence of fluid motion. Oceanogr Mar Biol Annu Rev 34:71-107

Kiørboe T (1993) Turbulence, phytoplankton cell size, and the structure of pelagic food webs. Adv Mar Biol 29:1-72

Kiørboe T, Saiz E (1995) Planktivorous feeding in calm and turbulent environments, with emphasis on copepods. Mar Ecol Prog Ser 122:135-145

Leclercq N, Gattuso, JP, Jaubet J (1999) Measurement of oxygen metabolism in open-top aquatic mesocosms: application to a coral reef community. Mar Ecol Prog Ser 177:299-304

Le Fèvre J, Frontier S (1988) Influence of temporal characteristics of physical phenomena on plankton dynamics, as shown in North-West European marine ecosystems. In: Rothschild BJ (ed) Toward a theory on biological-physical interactions in the world ocean. Kluwer Academic Publishers, Dordrecht, p 245-272

Legendre L (1981) Hydrodynamic control of marine phytoplankton production: the poaradox of stability. In: Nihoul JCJ (ed) Ecohydrodynamics. Oceanography Series 32. Elsevier Scientific Publishers, Amsterdam, p 191-207

Legendre L, Demers, S, Lefaivre D (1986) Biological production at marine ergoclines. In: Nhoul JCJ (ed) Marine interfaces hydrodynamics, Proc 17th Int Liège Colloq Ocean Hydrodyn. Oceanography Series 42. Elsevier Scientific Publishers, Amsterdam, p 1-29

Maar M, Arin L, Simó R, Sala MM, Peters F, Marrasé C (2002) Combined effects of nutrients and small-scale turbulence in a microcosm experiment. II. Dynamics of organic matter and phosphorus. Aquat Microb Ecol 29:63-72

MacKenzie BR, Miller TJ, Cyr S, Legget WC (1994) Evidence for a dome-shaped relationship between turbulence and larval fish ingestion rates. Limnol Oceanogr 39:1790-1799

Editorial responsibility: Otto Kinne (Editor),

Oldendorf/Luhe, Germany
Margalef R (1978) Life-forms of phytoplankton as survival alternatives in an unstable environment. Oceanol Acta 1: 493-509

Marrasé C (1986) Experimentos multifactoriales con plancton marino en microcosmos. PhD thesis, University of Barcelona

Marrasé C, Costello JH, Granata T (1990) Grazing in a turbulent environment: II. Energy dissipation, encounter rates and efficacy of feeding currents in Centropages hamatus. Proc Natl Acad Sci USA 87:1653-1657

Morán XAG, Estrada M (2001) Short-term variability of photosynthetic parameters and particulate and dissolved primary production in the Alboran Sea (SW Mediterranean). Mar Ecol Prog Ser 212:53-67

Nixon SW, Alonso D, Pilson MEQ, Buckley BA (1980) Turbulent mixing in aquatic mesocosms. In: Giesy JP (ed) Microcosms in ecological research. National Technical Information Service, Springfield, VA, p 818-849

Omori M, Ikeda T (1984) Methods in marine zooplankton ecology. John Wiley \& Sons, New York

Peters F, Marrasé C (2000) Effects of turbulence on plankton: an overview of experimental evidence and some theoretical considerations. Mar Ecol Prog Ser 205:291-306

Peters F, Redondo JM (1997) Turbulence generation and measurement: application to studies on plankton. Sci Mar 61(Suppl 1):205-228

Peters F, Marrasé C, Gasol JM, Sala MM, Arin L (1998) Effects of turbulence on bacterial growth mediated through food web interactions. Mar Ecol Prog Ser 172:293-303

Peters F, Marrasé C, Havskum H, Rassoulzadegan F, Dolan J, Alcaraz M, Gasol JM (2002) Turbulence and the microbial food web: effects of bacterial losses to predation and community structure. J Plankton Res 24:321-331

Petersen JE, Chen CC, Kemp WM (1997) Scaling aquatic primary productivity: experiments under nutrient- and lightlimited conditions. Ecology 78:2326-2338

Petersen JE, Sanford LP, Kemp WM (1998) Coastal plankton responses to turbulent mixing in experimental ecosystems. Mar Ecol Prog Ser 171:23-41

Rothschild BJ, Osborn TR (1988) Small-scale turbulence and plankton contact rates. J Plankton Res 10:465-474

Saiz E, Alcaraz M, Paffenhöfer GA (1992) Effects of smallscale turbulence on feeding rate and gross-growth efficiency of three Acartia species (Copepoda: Calanoida). J Plankton Res 14:1085-1097

Søndergaard M, Williams PJLeB, Cauwet G, Riemann B, Robinson C, Terzic S, Woodward EMS, Worm J (2000) Net accumulation and flux of dissolved organic carbon and dissolved organic nitrogen in marine plankton communities. Limnol Oceanogr 45:1097-1111

Williams PJLeB (1998) The balance of plankton respiration and photosynthesis in the open oceans. Nature 394:55-57

Williams PJLeB, Raine RCT, Bryan JR (1979) Agreement between the ${ }^{14} \mathrm{C}$ methods of measuring phytoplankton production: reassessment of the photosynthetic quotient. Oceanol Acta 2:411-416

Yentsch CS, Menzel DW (1963) A method for the determination of phytoplankton chlorophyll and pheophytin by fluorescence. Deep-Sea Res 10:221-231

Submitted: November 13, 2001; Accepted: May 31, 2002 Proofs received from author(s): September 17, 2002 